\title{
Rupture of major bronchi resulting from closed chest injuries
}

\author{
JOHN P. COLLINS, V. KETHARANATHAN, and \\ IAN MCCONCHIE
}

\section{Cardiothoracic Unit, The Royal Melbourne Hospital}

Four cases of ruptured bronchus following closed chest trauma are described. All injuries resulted from motor vehicle accidents and were diagnosed and treated within 24 hours of admission to the hospital. A satisfactory result followed early suture repair of the ruptured bronchus in three cases. One patient died during pneumonectomy. The early diagnosis and treatment of the condition are discussed.

\section{CASE REPORTS}

CASE 1 An 18-year-old boy was injured in a motor car accident on 1 February 1971. On admission he was found to have fractured second and third right ribs and a right-sided tension pneumothorax. An intercostal catheter connected to underwater drainage was inserted. Initially there was a large air leak but this ceased. However, the lung did not expand (Fig. 1). A suspected diagnosis of ruptured bronchus was confirmed by bronchoscopy and selective bronchial intubation. A right thoracotomy was performed and a tear in the anterior wall of the right main bronchus extending into the middle and lower lobe bronchi was found. The edges were trimmed

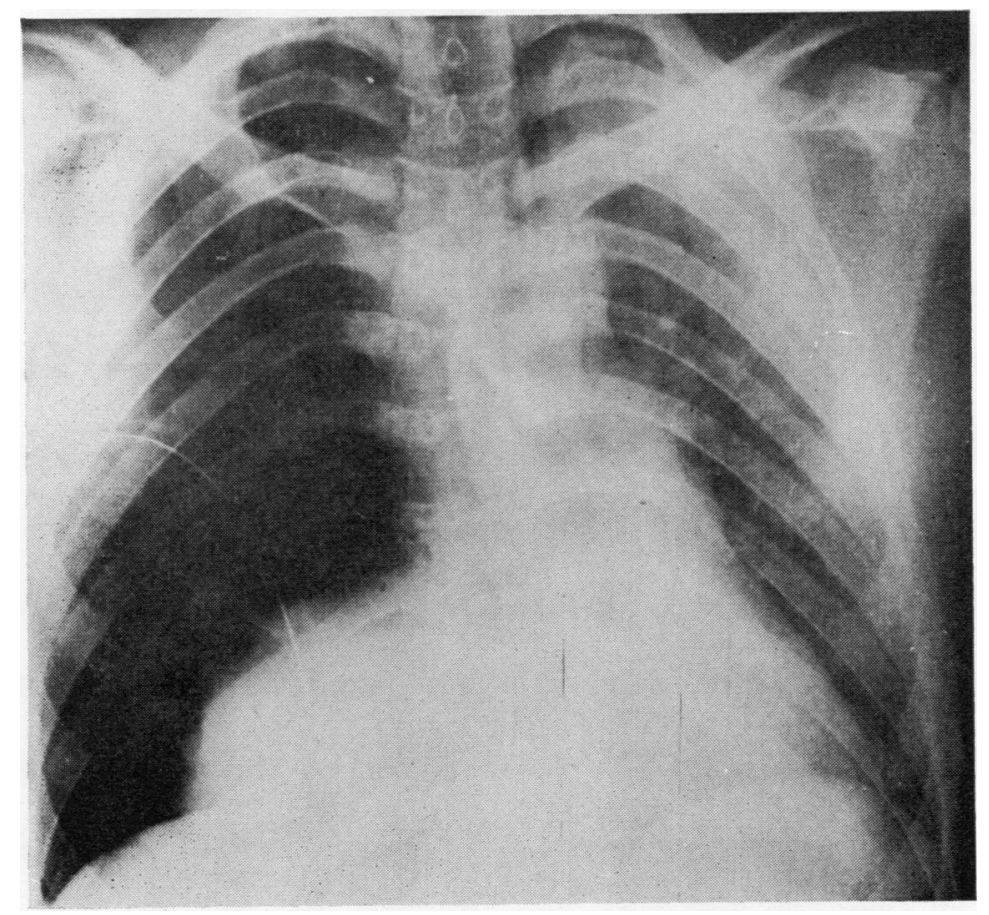

FIG. 1. Case 1. Preoperative chest film showing right pneumothorax and surgical emphysema despite intercostal catheter drainage. 
T A B L E

\begin{tabular}{|c|c|c|c|c|c|c|}
\hline Case & Age (yr) & Type of Injury & Associated Injury & Bronchial Injury & Operation & Outcome \\
\hline 2 & 18 & $\begin{array}{l}\text { High speed } \\
\text { steering } \\
\text { wheel }\end{array}$ & Concussion & $\begin{array}{l}\text { Longitudinal Y-shaped } \\
\text { tear on anterior wall of } \\
\text { right main bronchus } \\
\text { and middle and lower } \\
\text { lobe bronchi } \\
\text { Circumferential division } \\
\text { of right main bronchus } \\
\text { with retracted ends }\end{array}$ & $\begin{array}{l}\text { Thoracotomy. Primary } \\
\text { anastomosis of the right } \\
\text { main bronchus }\end{array}$ & $\begin{array}{l}\text { Stenosis of intermediate } \\
\text { and middle lobe bronchi. } \\
\text { Normal tracheobronchial } \\
\text { tree following broncho- } \\
\text { scopy and dilatation as } \\
\text { demonstrated by } \\
\text { subsequent bronchoscopy } \\
\text { and bronchography } \\
\text { Normal tracheobronchial } \\
\text { tree as demonstrated by } \\
\text { postoperative broncho- }\end{array}$ \\
\hline 3 & 20 & $\begin{array}{l}\text { Thrown } \\
\text { from motor } \\
\text { vehicle }\end{array}$ & $\begin{array}{l}\text { Severe cerebral } \\
\text { contusion }\end{array}$ & $\begin{array}{l}\text { Almost complete cir- } \\
\text { cumferential division of } \\
\text { right upper lobe } \\
\text { bronchus at its origin } \\
\text { from the right main } \\
\text { bronchus }\end{array}$ & $\begin{array}{l}\text { Thoracotomy. Primary } \\
\text { anastomosis of right } \\
\text { upper lobe to right } \\
\text { main bronchus }\end{array}$ & $\begin{array}{l}\text { Normal tracheobronchial } \\
\text { tree as demonstrated by } \\
\text { postoperative broncho- } \\
\text { scopy and broncho- } \\
\text { graphy. Employable but } \\
\text { inability to concentrate } \\
\text { suggests residual } \\
\text { cerebral defect }\end{array}$ \\
\hline 4 & 46 & $\begin{array}{l}\text { High speed } \\
\text { steering } \\
\text { wheel }\end{array}$ & $\begin{array}{l}\text { Cerebral } \\
\text { contusion }\end{array}$ & $\begin{array}{l}\text { Complete circumfer- } \\
\text { ential division of the } \\
\text { right main bronchus } \\
\text { plus a longitudinal tear } \\
\text { of the posterior } \\
\text { membranous wall of the } \\
\text { intrathoracic trachea }\end{array}$ & $\begin{array}{l}\text { Tracheostomy. Left } \\
\text { thoracotomy, internal } \\
\text { cardiac massage, right } \\
\text { thoracotomy, right } \\
\text { pneumonectomy }\end{array}$ & Death \\
\hline
\end{tabular}

All patients male, none wore safety belt

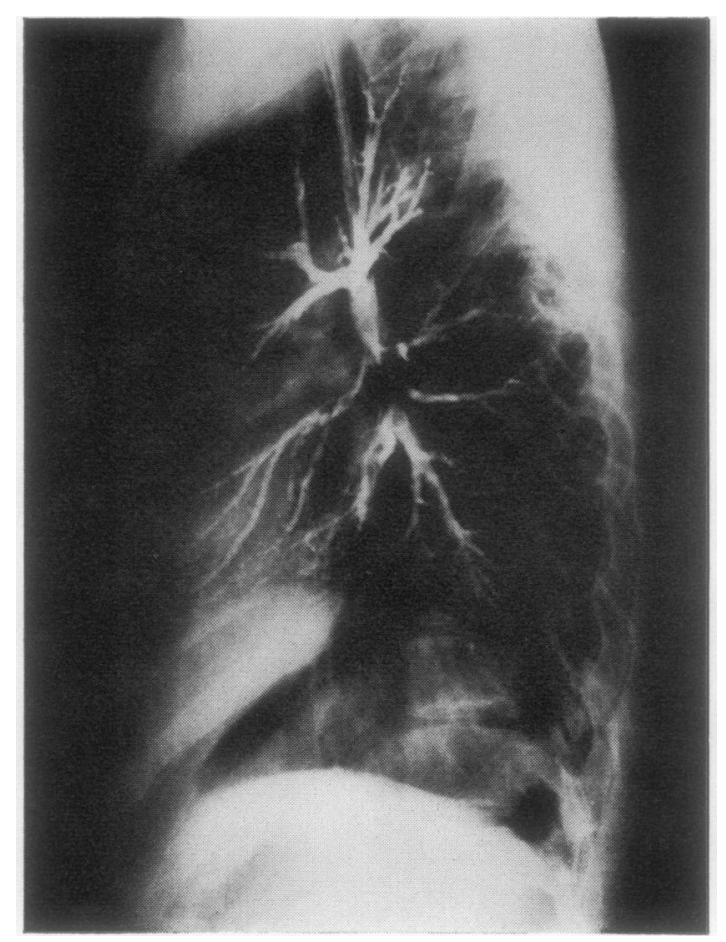

FIG. 2. Case 1. Lateral bronchogram showing stenosis of lower lobe bronchus. 
and anastomosed with 3-0 interrupted Dacron sutures. His postoperative course was uncomplicated and he was discharged from hospital 14 days after operation.

Three months later he complained of cough, purulent sputum, and right-sided pleuritic chest pain. A chest radiograph revealed areas of patchy consolidation in the right middle and lower lobes, and a bronchogram showed narrowing of the right intermediate bronchus (Fig. 2). At bronchoscopy a granuloma was removed from the anterior wall of the middle lobe bronchus, and the stenosed lower lobe bronchus was dilated with the adolescent bronchoscope. Subsequent bronchoscopy and bronchography did not show recurrent stenosis and the patient is now symptom-free.

CASE 2 A 26-year-old man was admitted to The Royal Melbourne Hospital on 15 December 1961 following a motor vehicle accident in which his right chest was injured by the steering wheel. He was very dyspnoeic and examination revealed a fractured second right rib and a right-sided tension pneumothorax. An intercostal catheter connected to underwater drainage was inserted. A large air leak persisted and the lung did not expand. Bronchoscopy revealed division of the right main bronchus. At thoracotomy the separated ends of the right main bronchus were trimmed and anastomosed with 3-0 silk. The patient convalesced satisfactorily and was discharged on the seventeenth postoperative day. Review bronchoscopy revealed a right main bronchus of normal diameter and the patient has remained symptom-free.

CASE 3 A 20-year-old man was thrown from a motor vehicle one hour before his admission to The Royal Melbourne Hospital on 19 March 1971. He sustained chest and head injuries. Examination revealed a severely dyspnoeic, cyanosed patient with subcutaneous emphysema, multiple bilateral rib fractures, and a right-sided tension pneumothorax. An intercostal catheter connected to underwater drainage was inserted. A large air leak persisted and the lung did not expand (Fig. 3). The clinical diagnosis of ruptured bronchus was suspected following selective bronchial intubation and a bronchoscopy was not performed. At right thoracotomy the upper lobe bronchus was found to be partly avulsed from the main bronchus. The pulmonary vessels were intact as in the previously described cases. The torn bronchial edges were trimmed and anastomosed with 3-0 and 5-0 interrupted Dacron sutures. A tracheostomy was performed because of the combined chest and head injuries. The patient was well when discharged from hospital four weeks after the accident. Bronchoscopy and bronchography performed three months later showed a normal bronchial tree.

CASE 4 A 46-year-old man sustained a crushing chest injury in a motor car accident on 24 June 1967. On admission to hospital he was dyspnoeic and cyanosed. He had a right-sided tension pneumothorax, flail chest, and multiple bilateral rib fractures. After insertion of an intercostal catheter connected to under-

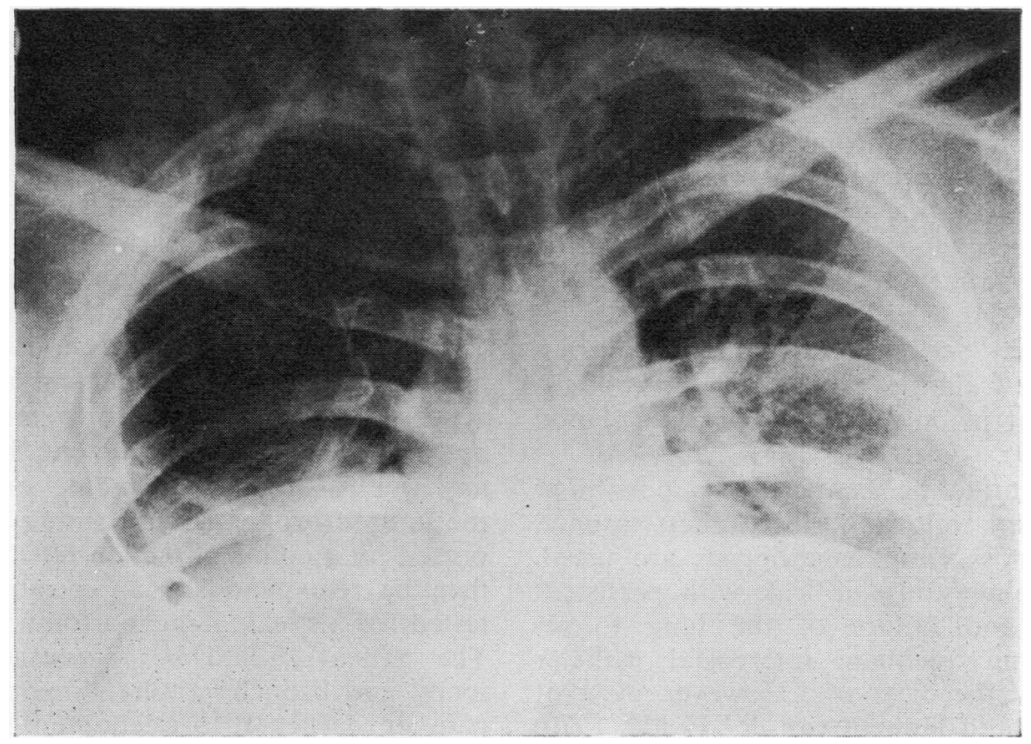

FIG. 3. Case 3. Preoperative chest film showing right pneumothorax and surgical emphysema despite intercostal catheter drainage. 
water drainage he remained severely dyspnoeic and a tracheostomy was performed. During this procedure he 'suffered a cardiac arrest and, through a rapidly performed left thoracotomy, internal cardiac massage was performed. At this stage a ruptured right main bronchus was suspected and a right thoracotomy showed a tear in the right main bronchus extending to the carina. A right pneumonectomy was performed. The patient failed to respond to resuscitative measures and died in the operating theatre.

\section{DISCUSSION}

Bronchial rupture is one of the serious intrathoracic visceral injuries resulting from closed chest trauma. It was reported as early as 1873 by Seuvre, but reports of primary repair did not appear until those of Griffith (1949) and Scannell (1951). Subsequently approximately 200 cases of traumatic bronchial rupture have been reported. Of these 68\% (Burke, 1962) were not diagnosed until septic atelectasis had developed. As the morbidity and mortality are significantly increased by delay it is important that those dealing with chest injury in the acute phase should be aware of the typical clinical picture of traumatic bronchial rupture.

Rupture of a major bronchus is usually a consequence of a high velocity motor vehicle accident. It can also be caused by crushing or twisting injuries. Several mechanisms have been suggested and include:

1. shearing of a pendulous lung from a fixed tracheobronchial tree due to rapid deceleration ;

2. an explosive force due to forced expiration against a closed glottis;

3. compression of the bronchus by the sternum or against the vertebral column.

Most of these injuries involve a main stem bronchus close to the carina. The right side is more commonly affected than the left (Battersby and Kilman, 1964). The pulmonary vessels are rarely damaged. Serious concomitant injuries, such as multiple fractures, head injury or abdominal injury, occur in only half of the cases (Hood and Sloan, 1959).

It is important to be aware of the possibility of such an injury following closed chest trauma. Dyspnoea, cyanosis, and haemoptysis are usual. A continued voluminous air leak with persistent pneumothorax and failure of the lung to reexpand following adequate intercostal catheter drainage suggest the diagnosis. However, $30 \%$ of cases (Eijgelaar and Homan van der Heide, 1970) do not have a pneumothorax because the mediastinal pleura may remain intact when a stem or lobar bronchus, or the intrathoracic trachea, is $\stackrel{\text { O }}{0}$ torn. Whether or not the mediastinal pleura is $\frac{\bar{O}}{\mathrm{C}}$ torn, air will always leak along the mediastinum $\overline{\bar{\omega}}$ to the deep tissue planes of the neck and thence $\widetilde{\Phi}$ to the subcutaneous tissues. Radiographic examination of the chest will demonstrate a pneumo- $\omega$ thorax and show the efficacy of intercostal drain- $\vec{O}$ age. It may also show mediastinal emphysema. An $\vec{\overrightarrow{ }}$ anteroposterior film of the neck should always be included as it will demonstrate deep cervical $\vec{F}$ emphysema even if mediastinal emphysema is not $\vec{x}$ obvious in the chest film (Eijgelaar and Homan $\infty$ van der Heide, 1970).

In all cases of suspected bronchial rupture a bronchoscopy should be performed and the site and extent of the injury noted.

A double-lumen endobronchial tube (Robert- $\vec{z}$ shaw) is useful both diagnostically and therapeutically in the assessment and management of $\overrightarrow{-}$ the condition. It can be used to demonstrate that the tear in the air passages is below the level of $\omega$ the bifurcation of the trachea and it enables one to demonstrate a voluminous air leak under controlled conditions. The patient's condition is im- $\overline{0}$ proved by the full inflation of the unaffected lung and decompression of the opposite tension $\mathbb{Q}$ pneumothorax. If it had been used in case 4 it $\overrightarrow{\vec{Q}}$ might have prevented hypoxaemic cardiac arrest. 3

If for any reason selective bronchial intuba-? tion is not possible then a bronchoscope should be introduced into the unaffected bronchus and this can be used for effective ventilation.

If the bronchial tear is seen to involve less than one-third of the circumference and if intercostal $\bar{\sigma}$ catheter underwater drainage results in complete and persistent re-expansion of the lung and eventual cessation of air leak, thoracotomy is not necessary. Otherwise thoracotomy, immediately윽 the diagnosis has been made, is indicated.

For repair of the ruptured bronchus a posterolateral thoracotomy should be performed and the $N$ torn bronchial ends identified, trimmed, approximated, and anastomosed using interrupted non- $\mathcal{O}$ absorbable atraumatic suture material with the $N$ knots placed outside the lumen ; $3-0$ or $5-0$ suture material is suitable depending on the calibre of the injured bronchus. The suture line can be sup- $\frac{\mathscr{C}}{\mathscr{C}}$ ported by a collar of Teflon felt. The lung should then be re-expanded using positive pressure and 7 tested for air leak. Tracheostomy is not necessary.

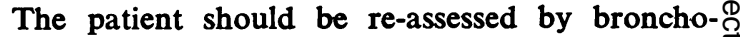
scopy and bronchography three months after re- $\overrightarrow{\mathbb{Q}}$ pair or earlier if bronchopulmonary symptoms $\sigma$ develop. If bronchial stenosis has occurred it can then be treated at an early stage. 
Many cases have been reported in which bronchial disruption was not diagnosed at the time of injury because the air leak had ceased due to bronchial occlusion by blood clot and subsequent fibrous occlusion. Persistent atelectasis, with or without subsequent episodes of lung infection, has led to the eventual diagnosis of the condition, which has been treated by either late bronchial anastomosis or pneumonectomy, depending on the degree of expandibilty or infection in the atelectatic lung (Gaafar et al., 1970; Maurer, Mendez, and Alexander, 1965 ; Battersby and Kilman, 1964).

\section{REFERENCES}

Battersby, J. S., and Kilman, J. W. (1964). Traumatic injuries of the tracheobronchial tree. Arch. Surg., 88, 644.
Burke, J. F. (1962). Early diagnosis of traumatic rupture of the bronchus. J. Amer. med. Ass., 181, 682.

Eijgelaar, A., and Homan van der Heide, J. N. (1970). A reliable early symptom of bronchial or tracheal rupture. Thorax, 25, 120.

Gaafar, H., Salama, M. R., Abu-Senna, G. O., Balbaa, A., and El-Mallah, S. H. (1970). Traumatic injuries of the bronchus. J. Egypt. med. Ass., 53, 13.

Griffith, J. L. (1949). Fracture of the bronchus. Thorax, 4, 105.

Hood, R. M., and Sloan, H. E. (1959). Injuries of the trachea and major bronchi. J. thorac. cardiovasc. Surg., 38, 458.

Maurer, E. R., Mendez, F. L., and Alexander, J. W. (1965). Modern methods of managing traumatic rupture and amputation of the bronchus. Dis. Chest, 48, 587.

Scannell, J. G. (1951). Rupture of the bronchus following closed injury to the chest. Report of a case treated by immediate thoracotomy and repair. Ann. Surg., 133, 127.

Seuvre, M. (1873). Ecrasement par une roue d'omnibusRupture de la bronche droite. Bull. Soc. anat., Paris, 48, 680 . 